\title{
Online Developmental Research: Observations from Moderated Studies
}

\author{
Güneş Öner ${ }^{a}$, Neslihan Oğuz ${ }^{b}$, Özdeş Çetin ${ }^{c}, S_{\text {Simge Ersönmez }}^{d}$, Pınar \\ Karan $^{\mathrm{e}}$, Mahmut Kurupınar ${ }^{\mathrm{f}}$, Oya Serbest ${ }^{\mathrm{g}}$ and Gaye Soley $^{\mathrm{h}}$
}

\begin{abstract}
The use of online tools for data collection has become increasingly prevalent in developmental research in recent years. While remote developmental studies offer significant advantages, adapting lab-based studies to remote conditions is a challenging process and requires researchers to consider various ethical, organizational, methodological and technical issues. The aim of this article is to facilitate this process by offering suggestions about some of these issues that arise when conducting online developmental research, focusing mainly on studies involving moderated sessions with infants and children. Different aspects of conducting remote developmental studies including ethics, participant recruitment, appointment scheduling, preparation of the materials and the set-up and execution of the live sessions are covered. Potential challenges associated with different stages are discussed with suggested solutions.
\end{abstract}

Article info

Keywords: Online developmental studies, remote research, live interview, looking time, childhood, infancy

Received: 13.05 .2021

Revised: 06.08.2021

Accepted: 25.08.2021

Published online: 15.09 .2021

\section{Online Developmental Research: Observations from Moderated Studies}

In recent years, technological advances have transformed research practices in developmental science, as well as in other fields. Various stages of research such as participant recruitment (Amon, Campbell, Hawke, \& Steinbeck, 2014; Gilligan, Kypri, \& Bourke, 2014; Thornton, Batterham, Fassnacht, Kay-Lambkin, Calear, \& Hunt,

${ }^{\mathrm{a}}$ Boğaziçi University, Department of Psychology, gunes.oner@boun.edu.tr, ORCID: 0000-0002-0312-6712

b Boğaziçi University, Department of Psychology, neslihan.oguz@boun.edu.tr, ORCID: 0000-0003-4980-0108

c Boğaziçi University, Department of Psychology, ozdes.cetin@boun.edu.tr, ORCID: 0000-0001-5007-1411

d Boğaziçi University, Department of Psychology, simge.ersonmez@boun.edu.tr, ORCID: 0000-0001-9212-1333

e Boğaziçi University, Department of Psychology, pinar.karan@boun.edu.tr, ORCID: 0000-0001-9895-0175

f Boğaziçi University, Department of Psychology, mahmut.kurupinar@boun.edu.tr, ORCID: 0000-0001-5376-1303

g Boğaziçi University, Department of Psychology, oya.serbest@boun.edu.tr, ORCID: 0000-0001-7442-4699

${ }^{\mathrm{h}}$ Corresponding author: Boğaziçi University, Department of Psychology,gaye.soley@boun.edu.tr, ORCID: 0000-0002-6333-6017 
2016), testing (e.g., Discoveries Online [Rhodes et al., 2020]; Lookit [Scott \& Schulz, 2017]; TheChildLab.com [Sheskin \& Keil, 2018]), coding (Chouinard, Scott, \& Cusack, 2019) and sharing the materials and data (e.g., the OSF [Foster \& Deardorff, 2017], The Child Language Data Exchange System - CHILDES [MacWhinney, 2000]; databrary.org [Adolph, Gilmore, \& Kennedy, 2017]) have increasingly moved to online platforms. While remote data collection has long been in place for other fields of psychology, developmental scientists started adopting online methods for data collection only in recent years (e.g., Chouinard et al., 2019; Chuey, Lockhart, Sheskin, \& Keil, 2020; Johnston, Sheskin, \& Keil, 2019; Kominsky, Gerstenberg, Pelz, Sheskin, Singmann, Schulz, \& Keil, 2021; Leshin, Leslie, \& Rhodes, 2020; Manning, Harpole, Harriott, Postolowicz, \& Norton, 2020; Nussenbaum, Scheuplein, Phaneuf, Evans, \& Hartley, 2020; Richardson, Sheskin, \& Keil, 2021; Scott \& Schulz, 2017; Scott, Chu, \& Shulz, 2017; Smith-Flores, Perez, Zhang, \& Feigenson, 2021; Soley \& Köseler, 2021; Tran, Cabral, Patel, \& Cusack, 2017). COVID-19 pandemic conditions have further spread the use of online research tools in many fields, including developmental science. In addition to the restrictions on in-person testing in the laboratories due to the pandemic, parents' and children's increasing reliance on online tools for education, work and socialization have potentially also contributed to the acceleration of this process.

Developmental researchers adopt different approaches in terms of how to conduct their studies remotely. Some use unmoderated online tools, where children complete the study by themselves with minimal guidance from their parents, but without interacting with a researcher (e.g., Discoveries Online [Rhodes et al., 2020], Lookit [Scott \& Schulz, 2017]). Moderated remote methods involve scheduling a live session with a researcher (e.g., Gweon, Sheskin, Chuey, \& Merrick, 2020; TheChildLab.com [Sheskin \& Keil, 2018]). The duration and the nature of remote studies also vary greatly, allowing to address diverse research questions. For instance, studies done with children include short tasks (10-to-20 minutes) such as showing children animations and asking them questions about these (e.g., Chuey et al., 2020; Leshin et al., 2020) as well as longer tasks (e.g., 30-to-60 minutes) that require children to exhibit sustained concentration in order to make several repeated decisions (Nussenbaum et al., 2020). Online platforms are also used to collect language samples (Manning et al., 2020) and looking time data from infants (e.g., Scott et al., 2017; Smith-Flores et al., 2021). Importantly, through both moderated and unmoderated online studies, researchers seem to be able to collect data that are comparable to data from lab-based studies (e.g., Manning et al., 2020; Nussenbaum et al., 2020; Rhodes et al., 2020; Scott et al., 2017; Sheskin \& Keil, 2018; Smith-Flores et al., 2021; Soley \& Köseler, 2021), providing preliminary evidence about the reliability of these methods. These developments have also fuelled new approaches that might allow researchers from multiple institutions to use standardized protocols through a shared platform and work collaboratively on recruiting participants, conducting studies, sharing data and materials (e.g., Collaboration for Reproducible and Distributed Large-Scale Experiments-CRADLE [Sheskin et al., 2020]). Websites (e.g., https://ChildrenHelpingScience.com; https://lookit.mit.edu) that host several studies conducted in different laboratories are already in place, allowing families to learn about and participate in studies targeting children of various age groups. 


\section{Pedagogical Implications in Diverse Contexts}

Conducting studies remotely with infants and children involves various challenges. When adapting studies to remote conditions, researchers face several methodological decisions in order to navigate these challenges. Therefore, it is crucial that experienced researchers share their know-how about the process of moving developmental research to online platforms. There are already valuable resources to facilitate this process (e.g., Gweon et al., 2020; Sheskin \& Keil, 2018). As members of the Baby and Child Development Laboratory at Bogazici University, we have greatly benefited from these resources. Within the past year and a half, we also gained hands on experience by conducting remote research with infants and children between the ages of 4 to 12 , mainly running moderated studies. Here, our aim is to give an overview of different online methodologies and share our observations about different stages of conducting online developmental studies, focusing on studies involving live video interviews with children. We will also discuss certain practical and technical aspects of live looking time studies carried out with infants.

We believe the observations and insights we share here have important pedagogical implications. First, they will facilitate the process of adapting to remote conditions for researchers who are interested in conducting developmental studies with young children or infants from a distance in online settings, by allowing researchers to avoid the costly trial-error process. Second, they can be used to train undergraduate and graduate students working as research assistants in developmental laboratories conducting remote studies. Finally, the methodological details covered in this article might also be informative for both undergraduate and graduate level Psychology students, given that they include important aspects of research methodology for behavioural research conducted online.

\section{Live Interviews with Children}

Conducting developmental studies in the laboratory is invaluable as it provides the opportunity for in-depth observation using a variety of techniques in a controlled environment. While online studies cannot entirely replace research taking place in laboratories given the limitations about implementing various methodologies online, they can nevertheless address certain limitations of lab-based studies and offer an alternative to some of these studies. The cost of and difficulties in bringing families to the laboratory, limitations in reaching out to diverse samples, observing children and infants in an environment that is unfamiliar to them, variability in research environments limiting the generalizability of findings, observer bias, and social desirability can be listed as some of these limitations (Rhodes et al., 2020). Unmoderated studies (e.g., Lookit [Scott \& Schulz, 2017]) that do not require the participant to interact with the researcher can eliminate many of these issues (Rhodes et al., 2020). These studies allow to attain larger sample sizes, avoid social desirability and experimenter bias and errors, reach out to certain populations that are normally difficult to recruit, conduct repetitive studies with the same participants, and to have a more standardized protocol that can be followed by different researchers and laboratories (Rhodes et al., 2020; Scott \& Schulz, 2017). While online methods that involve the 
researcher and the participant to interact via video conferencing platforms (e.g., Sheskin \& Keil, 2018) do not eliminate all limitations of lab-based studies, they also provide many advantages such as allowing participants from different backgrounds to take part in research studies more easily and at a low cost, increasing the possibility to participate in successive studies, facilitating replications as well as decreasing dropout rates in longitudinal studies (Rhodes et al., 2020; Scott \& Schulz, 2017; Sheskin et al., 2020). Having a researcher present during each study session may still be prone to issues related to bias and cause the sample size to remain small compared to fully automated studies. However, conducting the study with a trained researcher instead of parental guidance enables implementing study designs that would not be feasible in unmoderated studies (e.g., Bambha \& Casasola, 2021). In addition, a trained researcher can monitor the participant throughout the session and respond to cues about the participant's comprehension, distraction, and boredom level, and this might help increasing the quality of the data and decreasing the number of exclusions. Thus, conducting research via online video interviews can be considered as an alternative to some laboratory-based studies and can save time and resources for both the participants and the researchers, as well as allowing participation from diverse geographical and socio-economic backgrounds.

In the next section, we provide an overview of the procedure of online studies in the form of live interviews with children. We list some challenges along with suggestions about the execution of different stages of online studies. Specifically, we will cover ethical issues, preparation of online study materials and the set up, participant recruitment, scheduling appointments and execution of the live interviews.

\section{Before the Study}

\section{Ethics}

An important ethical issue that needs to be considered is how to obtain informed consent for online studies with children and infants. During studies conducted in the laboratory, usually, parents or guardians are informed about the study verbally by the researcher and then asked to give consent by wet-signing the informed consent document to indicate their approval of the participation of their children. In remote studies, other methods such as obtaining an electronic signature, getting approval via email/SMS, marking an online checkbox, requesting a wet-ink signature via post or getting a verbal approval can be considered as alternatives (Hokke et al., 2018), depending also on the specific requirements of the IRBs (institutional review board). In case informed consent needs to be obtained during the study in the form of verbal statement, the consent form can be shared with the parents beforehand via e-mail, along with detailed information about the study. This would give parents a chance to read everything carefully and ask any questions they might have via e-mail or during the session before the experiment begins. During the live session, parents should be reinformed about the study verbally by the experimenter and encouraged to ask any questions they may have. When parents give consent verbally, it is important to record it in video format as proof. For this, parents might be asked to indicate their name, date, the name of the study and that they agree their child to take part in the study. To make 
the process easier, the researcher can prepare a text including all the information and the parent might simply read this text out loud while the researcher takes an audio or video recording of the parent. As usual, this recording should be kept separately from the recording of the experimental session for ensuring the anonymity of the data. Relatedly, getting children's approval or assent to participate in the study is a standard procedure for in-lab studies and it should also be included in online studies in addition to getting consent from parents.

Protecting the privacy of participants and assuring the security of data are crucial requirements of any scientific study. Traditionally, data, including video or audio recordings, hardcopies of questionnaires and consent forms are kept in passwordprotected hard drives of the laboratory space and only researchers can have access to them. When studies are conducted online, on the other hand, data are collected in digital format by multiple researchers in different locations. This would require alternative solutions to be considered to secure the data. For instance, keeping the recordings of study sessions on multiple computers used by multiple researchers would not be safe, given that in case the device is stolen, damaged or lost, someone other than the researchers might have access to data or the data can be lost. If the studies have to be conducted on multiple computers, the data should be frequently transferred to passwordprotected computers or hard drives in the secure laboratory space. A better alternative, which is already in use by different research groups (e.g., Rhodes et al., 2020) would be to use secure web servers provided by the universities and save data to these servers. A critical and complicated issue related to ethics is data ownership. When using online platforms that are hosted by other countries, it is important to keep in mind that these platforms usually keep a copy of the data on their server. In these kinds of situations, additional GDPR (General Data Protection Regulation) data agreements or universityspecific protocols might be necessary.

Compared to lab-based studies, remote studies have the advantage that children might feel more comfortable during the study, given that they would be taking part in the study in a familiar environment instead of an unfamiliar laboratory space. On the other hand, in a study conducted in the laboratory, the experimenter has the opportunity to engage in a short conversation and warm up trials together with the child to make him/her feel comfortable in case the child feels shy or nervous. In an online study, establishing this connection, comforting the child and encouraging them to interact with the experimenter might be more challenging. Accordingly, researchers might want to also consider this potential challenge when designing online studies and take necessary steps (e.g., preparing fun warm up activities, sparing more time for the warm up) to prevent the child from feeling stressed about interacting with a researcher online.

\section{Organization of Virtual Lab Schedule}

Because remote studies do not require a physical space nor research assistants to be physically present in the laboratory, multiple concurrent studies can be scheduled, allowing for a much more flexible testing schedule. Different laboratories have different ways about how to organize testing schedules (see Gweon et al., 2020). For instance, some laboratories have multiple research assistants trained on a number of studies, so that each can run those studies online. Others match each assistant with a particular 
study, so that those studies are scheduled specifically when the responsible and trained assistants are available. Each of these options have advantages and disadvantages, and researchers might make their decision depending on the number of the studies and the assistants available. To arrange an appointment with the family, researchers might offer a few options to the parent. Alternatively, they may also ask the family for their preferred day and time and the researchers adjust themselves accordingly.

\section{Preparation of Materials}

In lab-based studies, it might be easier for researchers to monitor cues to children's comprehension of the material or their level of distraction or boredom. If, for instance, the researcher notices that the child does not follow the instructions, further explanations can be given about the procedure to clarify it and can keep the child's interest in the task by directing their attention to the stimuli or changing the tone of voice. In remote studies, on the other hand, the materials such as PowerPoint slides, videos, or audio recordings are shared on the child's computer screen in a physically different environment, so the researcher's control is much more limited. Thus, keeping children's attention on the material can be more challenging compared to lab-based studies. Further, the researchers have no control over the environment the child is in during remote studies. Since children usually participate in online studies at home, the environment can have various potential distractors. For instance, even when parents are warned in advance about the importance of the study taking place in a quiet place, siblings, pets or other family members are sometimes in the same room or the TV might be on in the background, increasing the likelihood of distraction and difficulty following what the study instructions. Given these, even when the study involves, for instance, the experimenter asking the child simple open-ended questions, using some visuals/sounds might help to keep the child's attention on the task. The researchers should first ensure that the material presented to the child is simple and easy to follow. If there are images, they should be placed on the child's screen in the right size and without any obstruction (i.e., the videos of the researcher and the child do not block the visual stimuli). Progressing from one stimulus or question to the next should be at the right pace such that the child can follow it easily, without getting bored.

In online studies, a display where the child cannot see the researcher's face but only hear his/her voice may not work well given that it may cause the child not to comprehend the instructions. Likewise, it may be distracting for children to see their own videos next to the video of the researcher on the screen. The child or the parent might be asked to close their own video so that they only see the experimenter's video on the screen throughout the study unless the design of the research requires otherwise. If these decisions are made beforehand, depending on the design of the stimuli presentation, the child or the parent can be asked to make necessary arrangements on the display before the experiment starts. For this, additional slides with instructions on how to make the necessary adjustments on the display can be added to the presentation used during the video conference (e.g., Gweon et al., 2020). It is also important to note that the layout of the videos differs depending on the online platform (e.g., Zoom, Adobe) and the electronic device used (e.g., laptop, tablet, or smartphone). Thus, the layout decisions such as which part of the screen the video will be or whether it needs to be 
moved to the top or to the side should be made according to the online platform and electronic device or vice versa. As an example, it is possible to move and adjust the size of the videos of the participants on Zoom while using a computer, but not on a tablet or phone. All of these should be taken into consideration when preparing the study materials.

If video or audio files will be used, differences in the sound system of the device used by the participant, sound delays or freezing of the videos caused by the slow internet connection may disrupt the study flow. Such problems are likely to occur when the video is shared through a video-conference platform. A better alternative might be to refer to websites (e.g., https: // w2g.tv) that allow simultaneous viewing of videos on many online video platforms such as Youtube, Vimeo, and Netflix, under the control of the researcher. This option should be considered in cases where watching a video synchronously with the participant is essential for the study.

In lab-based studies, it is a common practice to show different visuals to the child representing different options to choose from and to ask to point to one of the visuals. In the case of online studies, it might be challenging to understand where the child is pointing to and this might cause loss of data. To avoid such ambiguities, the response options can be presented, for instance, with different colors attached to them so that the child can refer to the color of the preferred option (e.g., Kominsky et al., 2021; Sheskin \& Keil, 2018).

It is crucial to test how participating children would see and hear the stimuli to prevent potential technical problems including the delay between sounds and images, possible obscured parts in the presentation due to the layout of video-conference platforms, and display differences between different devices (e.g., computer, tablet or smartphone). In order to identify and solve these potential problems beforehand, the researchers are strongly suggested to run mock experiments on different types of devices (e.g., computer, tablet, or smartphone) to check whether the stimuli can be seen and heard properly on both sides.

\section{Reaching Out to Families}

Families' involvement in online research requires access to a device such as a desktop/laptop computer, a tablet or a smartphone. This makes the potential participant pool much larger than typical lab studies, given that people who are willing to travel to the lab are the ones who live in nearby neighborhoods and have the time and the resources to travel to take part in these activities. While online methods significantly increase the size of the potential participant pool, it might be challenging to recruit families for online studies, if the research group cannot reach out to families (e.g., if they don't have access to a large participant database). For online studies, in addition to their existing databases, researchers also use websites and social media (e.g., Facebook, Instagram, Twitter) to reach out to participants (Hokke et al., 2018; Rhodes et al., 2020). Recently, many developmental research laboratories started to have presence on social media and to use these platforms to attract parents as followers, for instance, by sharing findings of developmental research (e.g., https://www.instagram.com/bounbcl/). These platforms, in turn, can also be used to inform parents about ongoing studies and to recruit them. In addition to using social media ads and the existing participant databases, 
researchers can also advertise their studies by posting their studies on collective websites where studies from different laboratories are hosted (e.g., www.childrenhelpingscience.com). Also, in order to attract new families, help may be sought from families who previously participated in one of the studies. Such families might be asked to share their experiences with other families on their social media accounts or on online forums that include other parents. This strategy becomes particularly effective when parents with a high number of followers (i.e., influencers) share their experiences.

When using social media for recruitment purposes, a permanent link can be added to the social media profile of the research group to allow interested parents to fill out a brief form asking about basic information that would be initially sufficient to be able to see if the child is eligible for a given study (e.g., the child's age, gender and parent's contact information). This way, every time a parent comes across the lab's social media account, they would easily go to the link and fill out the form, even if they decide not to follow the account. Simple digital flyers, explaining the purpose of each study, the age range of children it aims to recruit, and the types of devices required for the study can be prepared for different studies and shared with families on social media. These flyers can also include the instructions about how to participate. Families following the instructions on the flyer can be directed to the participation form on the profile, so that they can simply click on the link and fill out the form. Other contact information including e-mail address and phone number should also be provided, in case some parents prefer to use those means of communication.

\section{Communicating with Families}

When parents exhibit interest in participating in a study, researchers usually contact the parent(s) with information about the details of the study to be conducted, the steps to be followed until the end of the study (e.g., what does study participation involve and whether it is a one-time participation or whether it involves multiple sessions), and ask the family about their available times to schedule the experiment. An additional aspect to consider for online studies might be that since not every parent is comfortable using certain electronic devices or video conference applications, it might be helpful to prepare a step-by-step guide on how to set up the necessary platform for the live session (e.g., how to set up the Zoom). This guide could include installation and user manual of the online interview platform or the application (e.g., the software to create a sound recording while the parent and the child play at home) to be used. It might also be helpful to indicate that a quiet, non-distracting environment where the child can be alone with the parent is preferred for the study to take place. Links to this guide and other relevant forms and questionnaires can be included in the email sent to the parents.

Children are usually quite eager to take part in these online studies and they may experience disappointment if the meeting is delayed or postponed/cancelled due to technical problems. In order to avoid such situations, the parent may be offered to have a short pilot session before their actual appointment. Although families and even children have become more familiar with online platforms for work or school, giving an opportunity to try the connection before the actual appointment may facilitate a smoother live session. It is important to note, also, that online appointments might be 
easier to forget than face-to-face appointments, so a reminder e-mail can be sent to the family 2 days before as well as on the day of the study.

\section{During the Study}

Running a live interview online does not fundamentally differ from a lab-based study. As in lab-based experiments, starting the meeting 10 minutes before the scheduled time would give the experimenter the opportunity to check whether there is a problem with the internet connection and the meeting link that is sent to the family, to have enough time to prepare the materials to be used, and to prevent the family from waiting if they arrive to the meeting a little early. It is important for the researchers to have the basic knowledge that would allow them to provide technical support in case the family experiences technical difficulties (e.g., explaining how to set up Zoom, how to connect to the meeting, etc.). The researcher might start the session by asking whether the parent and the child can see and hear him/her without trouble. If everything works well, the researcher can proceed to the necessary adjustments on the display (e.g., moving the video of the researcher to the appropriate corner of the display) by giving instructions to the parent or the child. If the study involves presenting stimuli, it is important to make sure that the child can see/hear the stimuli presented without any problems before proceeding to the experiment. Preparing a few slides with control stimuli and questions would allow checking such potential problems as well as allowing the child to get familiarized with the procedure. For instance, the child can be shown simple colors or different animals on the screen and asked to name them (e.g., Sheskin \& Keil, 2018; Soley \& Köseler, 2021).

Depending on whether the study session is recorded or not, the researcher should inform the parent and the child before starting the recording. Needless to say, if recording will be taken during the session, informed consent should have also been taken for the recording. If consent is given verbally by the parent, the researcher might take two separate recordings; one for the part where the parent read the informed consent form out loud, indicating they give consent, and another one that captures the experimental session. As mentioned earlier, these two files should be kept separately to ensure anonymity of the data. Preparing a checklist to remind all these steps to the research assistants might be helpful.

\section{After the Study}

Once the study is completed and the family is debriefed, a common practice in online developmental research is to give a virtual gift card as an incentive. In addition, a digital certificate might be emailed to the family. Given that with the online procedure, families tend to take part in multiple studies, the researchers can further incentivize this by offering different certificates with different achievement levels (e.g., "a thank you" certificate for the first participation, a "child scientist" certificate for the third time, etc.).

A digital flyer with the link to the study can be shared with the family along with the gifts so that they can share it with other families who might also be interested in participating. 


\section{Online Studies with Infants}

One of the biggest challenges of infancy research is to bring in families into the laboratories. While older children can sometimes be tested in their schools, in museums or other activity centers, so far infant testing has largely been restricted to the physical laboratory space, due to the greater need to control various aspects of the testing environment. Recent data coming from online infant studies, however, suggest that online tools for infant testing provide a great promise in addressing this crucial constraint in infancy research by providing preliminary evidence for the reliability of online looking time paradigms (e.g., Smith-Flores et al., 2021). These studies, even though cannot establish the rigorously controlled testing environment of the laboratory, nevertheless seem to provide comparable data to lab-based studies. Given that they take place in infants' homes, online studies might also allow infants to be more comfortable and relaxed during testing and have the potential to have lower fuss-out rates compared to lab-based studies.

The design and testing process of online infant studies depend on whether one wants to code infants' looking time or gaze direction during the study. Like in studies with children, conducting infant studies using online platforms does not always mean that the researcher will accompany the family. Some online infant study platforms and programs (e.g., Lookit [Scott \& Schulz, 2017], e-Babylab [Lo, Mani, Kartushina, Mayor, \& Hermes, 2021]) offer families the opportunity to participate in studies whenever they want, without a researcher's accompaniment. In these unmoderated studies, the looking time, gaze direction and listening time can be monitored after the study is completed through the video recording taken. On the other hand, some of the infant studies require live coding, that is, the presence and control of the researcher, depending on the design of the research. For instance, the researcher may want to determine in what order, how long, or how many times a series of audio or video used in the study will be presented, depending on the duration or direction of the infant's gaze. For such a research design, scheduling a live session will be necessary.

In our lab, we use PsychoPy-based (Peirce et al., 2019) online infant testing programme PyHab (Kominsky, 2019) to present stimuli and code infants' gaze. This program does not require programming skills and allows to run infant-controlled studies by presenting stimuli in real time and to code it live. We share Pyhab (Kominsky, 2019) stimuli presentation window with parents via Watch2gether to maximize synchronization of the videos watched by the parents and the researcher. We record the entire screen using Mac's default screen recording app for offline coding. Below, we will touch upon a few practical and technical aspects of conducting live looking time studies with infants that researchers may want to consider when designing their study.

\section{Before the Study}

\section{Preparation of the Set-up}

While the direction and duration of the infant's gaze can be easily monitored via online video meeting, researchers may employ different methods to present stimuli. Some may present stimuli by simply sharing their own screen during online meetings. Others may 
not prefer screen sharing considering the technical disadvantages of it (low video quality, delay, etc.). Depending on the stimulus presentation preferences, a study flow can be created with the standard or Slides.com ("Slides - Create and share presentations online", 2013) integrated version of PsychoPy-based (Peirce et al., 2019), Pyhab (Kominsky, 2019). Using "watch party" websites (e.g., Watch2gether) is another option. The researcher can invite parents to a watching room by simply sending a pre-prepared link during the online meeting and can share the stimulus window via these websites. In this way, all the parent has to do will be clicking the link and maximizing the video player. Given the technical adjustments that parents have to make when Zoom screen sharing (e.g., hiding meeting controls, hiding self-view, etc.) is done, this latter alternative seems more useful for minimizing parental effort and technical disadvantages of Zoom screen sharing. This option works better with some browsers than others, thus it would be good to do a number of dry runs before scheduling a participant to see which settings work best.

\section{Communicating with Families}

Given that parents of infants tend to be busy taking care of their infants they might be less likely than parents of older children to have time to read long e-mail texts. Thus, researchers might consider offering options such as giving information and making appointments by phone in addition to e-mail, in order to facilitate the scheduling process. Additionally, for parents who have difficulty in giving a precise appointment time due to their infants' unpredictable sleep patterns or mood, only the date of the appointment might be determined in advance, letting the parents to call in when it is a good time for them for testing.

Regardless of whether the parents can schedule an exact time or not, it might be helpful to inform the parents in advance about how to prepare for the study. For this, parents can be provided with an easy-to-follow guide that includes information on how the study will be carried out, how to set up Zoom, connect the meeting, watch the videos, etc.

\section{During the Study}

Most issues to be considered when conducting online child studies also apply to online studies with infants. There are, however, a few additional things to consider in online infant studies. First, reminding the instructions multiple times before and during the study will be helpful for parents of infants. Second, in infant studies, it is crucial to ensure that infants only see stimuli, not additional distractors like meeting control panels, on the screen they are viewing. Therefore, if Zoom screen-sharing option is used, the guidance of the researcher to parents in adjusting certain display settings such as disabling the presence of meeting control panels and thumbnail videos will be helpful. Also determining optimal sound level, the distance from the computer screen, and the lighting of the room will be useful for standardizing the procedure to a certain degree. A simple checklist for the researcher can be prepared to ensure that all preparation has been done before the testing session begins. 
During testing, in order to avoid parental interference, parents might be asked to turn away from the screen, close their eyes, or the babies could be seated on a high chair instead of their parents' lap.

\section{Unmoderated Studies}

The remote studies we focused on so far involved a live session with a researcher, pretty much like an in-lab study. The unmoderated studies, on the other hand, involve researchers preparing their studies in such a way that children would be able to participate on their own or with minimal guidance from their parents. These studies can be hosted by platforms such as Lookit or the Discoveries Online. These platforms have minor differences such as required programming expertise or the devices that can be used to participate in the study, so the researchers can choose between these platforms considering the design of the study. These platforms ensure the security of the data and privacy of the information of families (Rhodes et al., 2020). Given that anyone can take part in these studies, it is important to clarify the participation criteria, such as the age or linguistic group it targets. Researchers employing these unmoderated studies usually record the entire session via webcams. This allows to monitor parental interference and also to have a recording of the verbal consent.

Unmoderated studies eliminate time constraints and families can join the study at any time (for details of online unmoderated developmental studies, please see Scott \& Schulz, 2017; Rhodes et al., 2020). This allows researchers to reach out to more participants in a shorter time. The main disadvantage of this method is that the absence of a researcher during the testing process limits the control researchers might have over the environment. Children might interact with something else such as a toy, or caregivers/parents might interfere with the process. In a live session, the experimenter can have control over these interferences to some degree and this may lead to lower exclusion rates in studies with live interaction compared to unmoderated studies.

\section{Conclusion}

Switching from lab-based to remote studies is a challenging process and requires considering several issues including ethical matters related to consent and data storage and ownership, technical details such as optimising stimuli for a variety of set ups, methodological complications such as parental interference or little control over the testing environment, strategies for online participant recruitment, and organization of virtual lab schedules. Despite these challenges, remote studies are becoming increasingly prevalent not only because they made research possible during the pandemic, but also because they have several advantages. In addition to allowing for greater flexibility at a lower cost compared to in-lab studies, both live and unmoderated online studies also provide exciting opportunities for conducting large-scale studies with more standardized protocols and for reaching out to more diverse samples.

Even though online methods cannot fully replace lab-based studies, given their advantages, they will likely play a central role in developmental research in the future. Thus, it is crucial to closely examine data from remote developmental studies in terms of their sample characteristics, exclusion rates and quality, and systematically compare 
these to data from lab-based studies. For instance, while remote studies allow recruiting participants from more diverse backgrounds in terms of race, language, income, and parental education level (Rhodes et al., 2020; Scott \& Schulz, 2017), some evidence suggests that participants from certain SES, racial or ethnic brackets might still be overrepresented in online studies (Leshin et al., 2020; Rhodes et al., 2020). These insights are valuable, as they allow researchers to have a better understanding of the strengths and limitations of remote studies and take the necessary steps for improving them.

As a future direction, online developmental research could benefit from interdisciplinary work that would allow researchers to use more interactive online platforms. Platforms where participating children can interact with an experimenter in a more active manner, could potentially allow conducting research that might be challenging to conduct online via live interviews or unmoderated studies. Such platforms could enable children, for instance, to actively play games with the experimenter or with other children and might enhance children's attention and interest compared to presentation-based studies. Certain programs to facilitate online coding during the studies such as simultaneous coding of forced-choice answers could also facilitate online research process.

\section{Authors' Note}

The writing of this article was supported by Boğaziçi University Research Fund Grant Number 20B07P2 to G.S, and it was prepared in accordance with the principles of research and publishing ethics.

\section{References}

Adolph, K. E., Gilmore, R. O., \& Kennedy, J. L. (2017). Video data and documentation will improve psychological science. Psychological Science Agenda, 31(10). http://www.apa.org/science/about/psa/2017/10/video-data

Amon, K. L., Campbell, A. J., Hawke, C., \& Steinbeck, K. (2014) Facebook as a recruitment tool for adolescent health research: A systematic review. Academic Pediatrics, 14, 439-447.e4. https://doi.org/10.1016/j.acap.2014.05.049

Bambha, V. P., \& Casasola, M. (2021). From lab to Zoom: Adapting training study methodologies to remote conditions. Frontiers in Psychology, 12, 3075. https://doi.org/10.3389/fpsyg.2021.69472

Chouinard, B., Scott, K., \& Cusack, R. (2019). Using automatic face analysis to score infant behaviour from video collected online. Infant Behavior and Development, 54, 1-12. https://doi.org/10.1016/j.infbeh.2018.11.00

Chuey, A., Lockhart, K., Sheskin, M., \& Keil, F. (2020). Children and adults selectively generalize mechanistic knowledge. Cognition, 199, 104231. https://doi.org/10.1016/j.cognition.2020.10423

Foster, E. D., \& Deardorff, A. (2017). Open science framework (OSF). Journal of the Medical Library Association: JMLA, 105(2), 203-206. https://doi.org/10.5195/jmla.2017.88 
Hokke, S., Hackworth, N.J., Quin, N., Bennetts, S.K., Win, H.Y., Nicholson, J.M., Zion, L., Lucke, J., Keyzer, P., \& Crawford, S. B. (2018). Ethical issues in using the internet to engage participants in family and child research: A scoping review. PLoS ONE, 13(9), e0204572. https://doi.org/10.1371/journal.pone.020457

Gilligan, C., Kypri, K., \& Bourke, J. (2014). Social networking versus Facebook advertising to recruit survey respondents: A quasi-experimental study. Journal of Medical Internet Research, 16. https://doi.org/10.2196/resprot.3317

Gweon, H., Sheskin, M., Chuey, A., \& Merrick, M. (Producers). (2020). Video-chat studies for online developmental research: Options and best practices [Webinar]. Retrieved June 15, 2021, from http://sll.stanford.edu/docs/Webinar_materials_v2.pd

Johnston, A. M., Sheskin, M., \& Keil, F. C. (2019). Learning the relevance of relevance and the trouble with truth: Evaluating explanatory relevance across childhood. Journal of Cognition and Development, 20(4), 555-572. https://doi.org/10.1080/15248372.2019.1631167

Kominsky, J. F. (2019) PyHab: Open-source real time infant gaze coding and stimulus presentation software. Infant Behavior \& Development, 54, 114-119. https://doi.org/10.1016/j.infbeh.2018.11.006

Kominsky, J. F., Gerstenberg, T., Pelz, M., Sheskin, M., Singmann, H., Schulz, L., \& Keil, F. C. (2021). The trajectory of counterfactual simulation in development. Developmental Psychology, 57(2), 253. https://doi.org/10.1037/dev0001140

Leshin, R., Leslie, S. J., \& Rhodes, M. (2020). Does it matter how we speak about social kinds? A large, pre-registered, online experimental study of how language shapes the development of essentialist beliefs. New York University. https://doi.org/10.31234/osf.io/nb6ys

Lo, C., Mani, N., Kartushina, N., Mayor, J., \& Hermes, J. (2021). e-Babylab: An opensource browser-based tool for unmoderated online developmental studies. https://doi.org/10.31234/osf.io/u73sy

MacWhinney, B. (2000) The CHILDES Project: Tools for Analyzing Talk. Lawrence Erlbaum Associates, Mahwah, NJ

Manning, B. L., Harpole, A., Harriott, E. M., Postolowicz, K., \& Norton, E. S. (2020). Taking language samples home: Feasibility, reliability, and validity of child language samples conducted remotely with video chat versus in-person. Journal of Speech, Language, and Hearing Research, 63(12), 3982-3990. https://doi.org/10.1044/2020_JSLHR-20-00202

Nussenbaum, K., Scheuplein, M., Phaneuf, C. V., Evans, M. D., \& Hartley, C. A. (2020). Moving developmental research online: Comparing in-lab and webbased studies of model-based reinforcement learning. Collabra: Psychology, 6(1). https://doi.org/10.31219/osf.io/vewyq

Peirce, J. W., Gray, J. R., Simpson, S., MacAskill, M. R., Höchenberger, R., Sogo, H., Kastman, E., \& Lindeløv, J. (2019). PsychoPy2: Experiments in behavior made easy. Behavior Research Methods. https://doi.org/10.3758/s13428-018-01193

Richardson, E., Sheskin, M., \& Keil, F. C. (2021). An illusion of self-sufficiency for learning about artifacts in scaffolded learners, but not observers. Child Development, 10.1111/cdev.13506. Advance online publication. https://doi.org/10.1111/cdev.13506 
Rhodes, M., Rizzo, M. T., Foster-Hanson, E., Moty, K., Leshin, R. A., Wang, M., Benitez, J., \& Ocampo, J. D. (2020). Advancing developmental science via unmoderated remote research with children. Journal of Cognition and Development, 21, 477-493. https://doi.org/10.1080/15248372.2020.1797751.

Scott, K., Chu, J., \& Schulz, L. (2017). Lookit (Part 2): Assessing the viability of online developmental research, results from three case studies. Open Mind, 1, 15-29. https://doi.org/10.1162/OPMI_a_00001

Scott, K. M., \& Schulz, L. E. (2017). Lookit (Part 1): A new online platform for developmental research. Open Mind, 1, 4-14. https://doi.org/10.1162/OPMI_a_00002

Sheskin, M., \& Keil, F. (2018). TheChildLab.com a video chat platform for developmental research. https://doi.org/10.31234/osf.io/rn7w5

Sheskin, M., Scott, K., Mills, C. M., Bergelson, E., Bonawitz, E., Spelke, E. S., Fei-Fei, L., Keil, F. C., Gweon, H., Tenenbaum, J. B., Jara-Ettinger, J., Adolph, K. E., Rhodes, M., Frank, M. C., Mehr, S. A., \& Schulz, L. (2020). Online developmental science to foster innovation, access, and impact. Trends in Cognitive Sciences, 24(9), 675-678. https://doi.org/10.1016/j.tics.2020.06.004

Slides. (2013) Slides - Create and share presentations online. [online] Available at: https://slides.com/ [Accessed 18 December 2020].

Smith-Flores, A. S., Perez, J., Zhang, M. H., \& Feigenson, L. (2021). Online measures of looking and learning in infancy. https://doi.org/10.31234/osf.io/tdbn

Soley, G., \& Köseler, B. (2021). The social meaning of common knowledge across development. Cognition, 215, 104811. https://doi.org/10.1016/j.cognition.2021.10481

Thornton, L., Batterham, P. J., Fassnacht, D. B., Kay-Lambkin, F., Calear, A. L., \& Hunt, S. (2016). Recruiting for health, medical or psychosocial research using Facebook: Systematic review. Internet Interventions, 4, 72-81. https://doi.org/10.1016/j.invent.2016.02.001

Tran, M., Cabral, L., Patel, R., \& Cusack, R. (2017). Online recruitment and testing of infants with Mechanical Turk. Journal of Experimental Child Psychology, 156, 168-178. https://doi.org/10.1016/j.jecp.2016.12.003. 


\section{Çevrim İçi Gelişim Araştırmaları: Araştırmacı Eşliğinde Yürütülen Çalışmalardan İzlenimler}

Öz

Çevrim içi araçlar, gelişim araştırmalarında veri toplama amacıyla son yıllarda giderek daha yaygın bir şekilde kullanılmaya bașlanmıștır. Uzaktan yürütülen gelișimsel çalıșmalar oldukça önemli avantajlar sağlamaktadır. Bununla birlikte, laboratuvarda yürütülen çalş̧maların çevrim içi koşullara uyarlanması zorlu bir süreç içermekte ve araștırmacıların etik, organizasyon, metodoloji ve teknik unsurlar gibi pek çok konuyu değerlendirmesini gerektirmektedir. Bu makalenin amact, temelde çocuklarla ve bebeklerle yapılan ve araștırmacı eşliğinde canlı yürütülen araştırmalara odaklanarak çevrim içi gelişim çalıșmaların yürütülmesindeki pratik ve teknik konulara dair çeşitli öneriler paylaşmak ve bu sayede araștırmacıların adaptasyon sürecini kolaylaşttrmakttr. Etik, katıllımcllara ulaşma, randevu oluşturma, deneysel materyallerin ve kurulumun hazırlanması ve canlı görüssmelerin yürütülmesi gibi çevrim içi gelişsim araștırmalarının farkl aşamaları ele alınmıştır. Bu farklı aşamalara dair zorluklar, önerilen çözümlerle birlikte tartışılmıştır.

Anahtar sözcükler: Çevrim içi gelişim çalışmaları, uzaktan araştırma, canlı görüşme, izleme süresi, çocukluk, bebeklik 